J. Lake Sci.(湖泊科学), 2018, 30(1): 139-149

DOI 10. 18307/2018. 0114

(c) 2018 by Journal of Lake Sciences

\title{
鄱阳湖流域赣江水系溶解态金属元素空间分布特征及污染来源”
}

\author{
李传琼 ${ }^{1,2}$, 王 鹏 ${ }^{1,2 * *}$, 陈 波 ${ }^{1,2}$, 李 燕 ${ }^{1,2}$ \\ ( 1 : 江西师范大学鄱阳湖湿地与流域研究教育部重点实验室,南昌 330022) \\ $(2:$ 江西师范大学地理与环境学院, 南昌 330022)
}

\begin{abstract}
摘 要: 于 2015 年 1 月和 7 月在赣江干流和主要支流 37 个采样点共采集 74 个水样,分析赣江水系 15 种溶解态金属元 素 $(\mathrm{Be} 、 \mathrm{Al} 、 \mathrm{~V} 、 \mathrm{Mn} 、 \mathrm{Fe} 、 \mathrm{Co} 、 \mathrm{Ni} 、 \mathrm{Cu} 、 \mathrm{As} 、 \mathrm{Mo} 、 \mathrm{Cd} 、 \mathrm{Sb} 、 \mathrm{Tl} 、 \mathrm{~Pb} 、 \mathrm{U})$ 的空间分布特征和污染来源的贡献率. 结果表明: 多数水样的溶 解态金属元素浓度符合水质标准, 主要的超标元素是 $\mathrm{Fe}$, 样品超标率为 $21.60 \%$, 其次为 $\mathrm{As}(8.10 \%) 、 \mathrm{Mn}(4.05 \%) 、 \mathrm{Tl}$ (4.05\%) 和 $\mathrm{Al}(1.35 \%) . \mathrm{Be} 、 \mathrm{Al} 、 \mathrm{~V} 、 \mathrm{Fe} 、 \mathrm{Co} 、 \mathrm{Ni} 、 \mathrm{Cu} 、 \mathrm{U}$ 浓度在枯水期显著高于丰水期,其他元素差异不显著. 依据溶解态金 属元素的空间分布特征, 赣江流域可分为 3 个区域: 湘水、章水和赣江赣州市段 ( C1), 桃江、袁水和锦江( C2), 其他区域 (C3) ; 溶解态金属元素水平大小排序为 $\mathrm{C} 1>\mathrm{C} 2>\mathrm{C} 3$, 其中 $\mathrm{Be} 、 \mathrm{Al} 、 \mathrm{Cu} 、 \mathrm{Mo} 、 \mathrm{Sb} 、 \mathrm{As}$ 浓度在 $\mathrm{C} 1$ 最高, $\mathrm{V} 、 \mathrm{Mn} 、 \mathrm{Fe} 、 \mathrm{Ni} 、 \mathrm{Cd}$ 浓度在 $\mathrm{C} 2$ 最高. 采矿废水、矿渣和农田土壤降雨淋滤、钢铁冶炼废水是赣江溶解金属元素的主要来源; $\mathrm{Be} 、 \mathrm{Al} 、 \mathrm{Cu} 、 \mathrm{~Pb} 、 \mathrm{U}$ 的污染 源超过 40\% 来自采矿废水, Cu、As、Mo、Cd 的污染源超过 35\% 来自矿渣和农田土壤降雨淋滤, V、Mn、Co、Ni 的污染源超过 $41 \%$ 来自钢铁冶炼废水.
\end{abstract}

关键词: 赣江;溶解态金属元素;工业废水;污染来源;重金属污染;鄱阳湖流域

\section{Spatial distribution and pollution source of dissolved metals in the Ganjiang River of Lake Poyang Basin}

\author{
LI Chuanqiong ${ }^{1,2}$, WANG Peng ${ }^{1,2 * *}$, CHEN Bo ${ }^{1,2} \&$ LI Yan ${ }^{1,2}$ \\ (1: Key Laboratory of Poyang Lake Wetland and Watershed Research, Ministry of Education, Jiangxi Normal University, Nan- \\ chang 330022, P.R.China) \\ (2: School of Geography and Environment, Jiangxi Normal University, Nanchang 330022, P.R.China)
}

\begin{abstract}
We collected 74 water samples from 37 sites along the Ganjiang River and its tributaries in January and July, 2015 to analyze the spatial distribution of dissolved metals ( $\mathrm{Be}, \mathrm{Al}, \mathrm{V}, \mathrm{Mn}, \mathrm{Fe}, \mathrm{Co}, \mathrm{Ni}, \mathrm{Cu}, \mathrm{As}, \mathrm{Mo}, \mathrm{Cd}, \mathrm{Sb}, \mathrm{Tl}, \mathrm{Pb}$ and $\mathrm{U}$ ), and to estimate the contributions of pollution sources in Lake Poyang Basin. The results showed that the concentrations of dissolved metals in most water samples met the national water quality standards, and $\mathrm{Fe}$ is the primary trace metal beyond the national standard, i.e. $21.60 \%$ of water samples had higher Fe concentrations than the national drinking water quality standard, followed by As $(8.10 \%)$, $\mathrm{Mn}(4.05 \%)$, $\mathrm{Tl}(4.05 \%)$ and $\mathrm{Al}(1.35 \%)$. In addition, the concentrations of $\mathrm{Be}, \mathrm{Al}, \mathrm{V}, \mathrm{Fe}, \mathrm{Co}, \mathrm{Ni}, \mathrm{Cu}$ and $\mathrm{U}$ during the dry season were significantly higher than those during the wet season, while others had no significant difference. Based on the spatial distribution of dissolved metals, three spatial regions were identified: C1 (Xiangshui River Basin, Zhangshui River Basin and Ganzhou section of Ganjiang River), C2 (Taojiang River Basin, Yuanshui River Basin and Jinjiang River Basin), and C3 (the other regions beyond $\mathrm{C} 1$ and $\mathrm{C} 2$ ). The contamination order in the three regions was $\mathrm{C} 1>\mathrm{C} 2>\mathrm{C} 3$. The highest concentrations of Be, $\mathrm{Al}, \mathrm{Cu}, \mathrm{Mo}, \mathrm{Sb}$ and As occurred in $\mathrm{C} 1$; while V, Mn, Fe, Ni and Cd in C2. The primary sources of dissolved metals in the Ganjiang River were mining waste water, leaching water of slag and agricultural soils, and steel industry waste water. We estimated that more than $40 \%$ of $\mathrm{Be}, \mathrm{Al}, \mathrm{Cu}, \mathrm{Pb}$ and $\mathrm{U}$ were from mining waste water, more than $35 \%$ of $\mathrm{Cu}$, As, Mo and Cd from leaching water of slag and agricultural soils, and more than $41 \%$ of $\mathrm{V}, \mathrm{Mn}$, Co and Ni from the steel industry waste water.
\end{abstract}

* 国家自然科学基金项目(41661017,41201033)、江西省自然科学基金项目(20151BAB213035)和江西省重大生态安 全问题监控协同创新中心项目 (JX-EW-00) 联合资助. 2016-11-28 收稿; 2017-04-17 收修改稿. 李传琼 (1990 ）, 女, 硕士研究生; E-mail: 17779145632@163.com.

** 通信作者; E-mail: wangpengjlu@jxnu.edu.cn. 
Keywords: Ganjiang River; dissolved metals; industrial wastewater; pollution source; heavy metal pollution; Lake Poyang Basin

河流是工农业生产和生活用水的来源, 也是水循环的重要场所. 金属元素经水循环进人河流, 因其稳定 的结构难降解于水体,即使微量进人水体,对环境也能起到一定的毒害作用 ${ }^{[1-3]}$. 自然和人类活动是金属元 素的主要来源, 人类活动如金属冶炼、采矿、工业废水排放和农业污水等已威胁到环境和人类身体的健 康 ${ }^{[4-5]}$. 因不合理的人类活动, 大量污染物进人河流, 导致河流水体金属元素含量超标, 引起了国内外学者的 关注 ${ }^{[6-7]}$. 河流水体中的金属元素可分为溶解态和颗粒态两种形态, 受人类活动污染的水体, 更多的金属元 素与有机质结合以自由离子态存在, 溶解态占有更大的比例 ${ }^{[8-9]}$.

鄱阳湖是我国最大的淡水湖泊, 也是生物多样性极其丰富的淡水湿地生态系统. 近年来, 随着流域矿产 开采和金属冶炼废水排放、工农业的发展及城市化的扩展, 湖区呈现出不同程度的重金属污染 ${ }^{[10]}$. 赣江是 鄱阳湖的第一大支流, 鄱阳湖 $\mathrm{Pb} 、 \mathrm{Zn} 、 \mathrm{Cu} 、 \mathrm{Ni} 、 \mathrm{As}$ 和 $\mathrm{Cd}$ 人湖通量的 $75.4 \% 、 56.8 \% 、 47.3 \% 、 30.6 \% 、 25.5 \%$ 和 $23.2 \%^{[11]}$ 来自赣江. 因此查明赣江流域溶解态金属元素的空间分布特征和污染来源, 对赣江流域的水环境 保护和鄱阳湖流域的污染防治具有重要意义. 已有研究表明,赣江流域可溶态 $\mathrm{Cd}$ 的浓度在中国 I 类地表水 环境质量标准 ${ }^{[12]}$, 仅赣江赣州市段和赣江吉安市段的可溶态 $\mathrm{Cd}$ 和 As 超出了中国 III类地表水环境质量标 准 ${ }^{[13]}$. 目前关于赣江金属元素的研究集中在时空分布 ${ }^{[13]}$ 和风险评价 ${ }^{[14]}$ 方面, 尚不清楚溶解态金属元素的 污染来源及不同污染来源的贡献率. 查明赣江流域溶解态金属元素的污染来源和污染来源的贡献率是进行 污染防治的基础. 本研究基于赣江水系枯水期和丰水期溶解态金属元素数据, 分析溶解态金属元素的空间 分布特征, 探讨溶解态金属元素的污染来源并估算污染来源的贡献率, 以期为赣江流域和鄱阳湖溶解态金 属元素污染的防治提供科学依据.

\section{1 材料与方法}

\section{1 研究区域概况}

赣江源于闽赣交界的武夷山区, 自南向北经赣州、吉安、宜春、南昌等城市进人鄱阳湖. 赣江流域属于亚 热带季风湿润气候, 年平均降雨量为 $1580 \mathrm{~mm}$, 径流量约占鄱阳湖水系总径流量的 $46.6 \%$. 赣州市和新干县 把赣江分为上、中、下游. 赣江上游流经矿产资源丰富的地区, 同时也流经了我国重要脐橙种植区; 中游流经 吉泰盆地水稻种植区; 下游流经宜春、新余、南昌等主要城市, 其中袁水和锦江沿岸煤矿和铁矿资源丰 富 ${ }^{[15-18]}$. 赣江流域主要的煤矿、铁矿和铇矿分布详见图 1.

\section{2 数据来源}

为研究赣江干流不同河段溶解态金属元素的污染来源, 对干流的上游、中游、下游设置若干个采样点 (用 $\mathrm{G}$ 表示) ; 为研究支流溶解态金属元素的污染来源, 在主要支流中下游设置若干个采样点 (用 $\mathrm{Z}$ 表示), 共设置了 37 个(图 1). 于 2015 年 1 月 (枯水期) 和 7 月 (丰水期) 分别对应赣江流域的干流和支流中央 50 $\mathrm{cm}$ 深的水样进行采集, 并现场用 GPS (GPS, MAP62sc, USA) 对采样点进行定位. 每次选用顺流采样方式, 每 个点位水样用 $500 \mathrm{ml}$ 的塑料瓶收集, 在实验室用 $0.45 \mu \mathrm{m}$ 孔径的醋酸纤维滤膜抽滤, 并加硝酸酸化至 $\mathrm{pH}<2$ 保 存于 $0 \sim 4^{\circ} \mathrm{C}$ 的环境下, 用于测定溶解态金属元素的浓度. 用电感耦合等离子体质谱仪 ( ICP-MS X Series, PE, $\mathrm{USA}$ ) 测定水样中 $\mathrm{Be} 、 \mathrm{Al} 、 \mathrm{~V} 、 \mathrm{Mn} 、 \mathrm{Fe} 、 \mathrm{Co} 、 \mathrm{Ni} 、 \mathrm{Cu} 、 \mathrm{As} 、 \mathrm{Mo} 、 \mathrm{Cd} 、 \mathrm{Sb} 、 \mathrm{Tl} 、 \mathrm{~Pb} 、 \mathrm{U}$ 的浓度. 样品在检测之前, 仪器利用 标准物质 (SRM, AccuStandard, Inc., USA) 进行 3 次重复检测并且进行极限检测, 这 15 种溶解态金属元素 的极限检测值分别为 $0.004 、 0.065 、 0.04 、 0.011 、 1.929 、 0.005 、 0.044 、 0.042 、 0.094 、 0.003 、 0.001924 、 0.004019$ 、 $0.004068 、 0.002338$ 和 $0.000159 \mu \mathrm{g} / \mathrm{L}$. 所有元素 2 次平行测样的相对标准偏差 (RSD) 均低于 $10 \%$.

\section{3 数据分析}

根据 15 种溶解态金属元素数据,运用单因素方差分析和聚类分析探讨了溶解态金属元素的空间分布 差异 ${ }^{[20]}$,并运用主成分分析识别溶解态金属元素的主要污染源.

绝对主成分得分/多元线性回归分析 (APCS-MLR) 是基于主成分得分进行的线性回归分析的一种受体 模型 ${ }^{[21]}$, 广泛用于定量估算污染源的贡献率 ${ }^{[22-25]}$. 由于主成分分析的结果保留的是标准化后的数据, 绝对 零值因子得分计算公式为: 


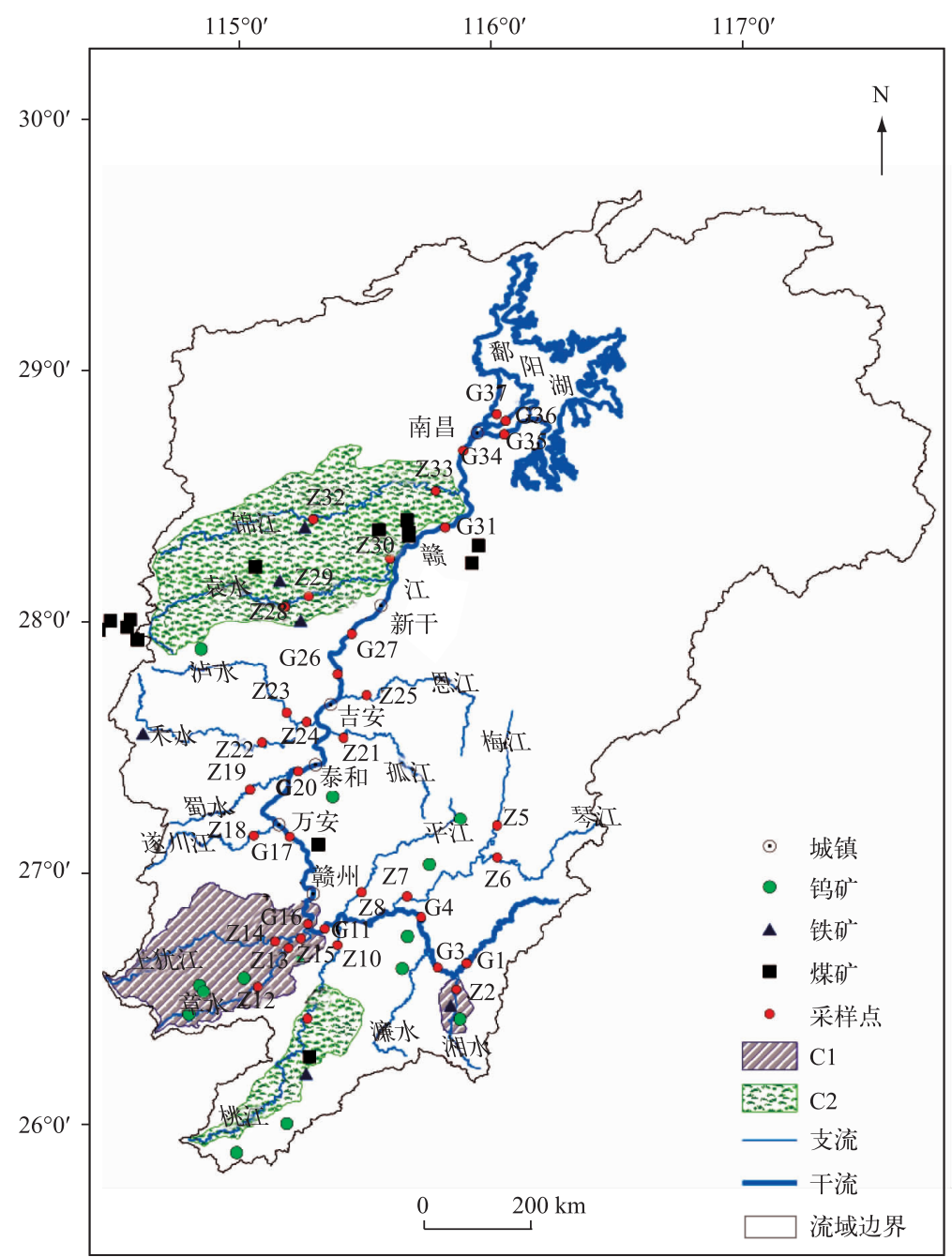

图 1 赣江水系采样位点分布 (C1、C2 分别为聚类分析 (见 2.3 节) 形成的区域. 煤矿、铁矿和铇矿分布根据

《江西省志》 ${ }^{[19]}$ 和赣州市环境信息发布平台 (http: //www.gzhb.gov.cn/infopublic/flexoutput/)绘制)

Fig. 1 Distributions of sampling sites in the Ganjiang River

$$
Z_{0}=\frac{0-c_{i}}{\sigma_{i}}=\frac{-c_{i}}{\sigma_{i}}
$$

式中, $i$ 为元素的种类数,其中 $c_{i}$ 和 $\sigma_{i}$ 分别代表第 $i$ 种元素平均浓度和第 $i$ 种元素的标准差.

绝对主成分得分通过 PCA 因子得分减去对应绝对零值因子得分估算. 进行线性回归分析(公式(2)), 获得回归系数及污染源贡献率:

$$
M_{j}=\delta_{0}+\sum_{k=1}^{p} \delta_{k} \cdot A P C S_{k j}
$$

式中, $M_{j}$ 为第 $j$ 个样品的元素浓度, $A P C S_{k j}$ 为第 $k$ 个污染源在第 $j$ 个样品旋转后的绝对主成分得分, $\delta_{k} \cdot A P C S_{k j}$ 为第 $k$ 个污染源在第 $j$ 个样品的贡献率, $\delta_{0}$ 是 PCA 分析中主要污染源之外的其他污染来源. 


\section{2 结果与讨论}

\section{1 溶解态金属元素空间分布特征}

赣江水系溶解态金属元素 $\mathrm{Be} 、 \mathrm{Al} 、 \mathrm{~V} 、 \mathrm{Fe} 、 \mathrm{Co} 、 \mathrm{Ni} 、 \mathrm{Cu} 、 \mathrm{U}$ 浓度枯水期显著高于丰水期,其他元素差异不显 著. $\mathrm{Al} 、 \mathrm{Ni} 、 \mathrm{Cu} 、 \mathrm{As} 、 \mathrm{Cd} 、 \mathrm{Sb} 、 \mathrm{~Pb} 、 \mathrm{U}$ 和 $\mathrm{Be} 、 \mathrm{~V} 、 \mathrm{Mn} 、 \mathrm{Fe} 、 \mathrm{Co} 、 \mathrm{Ni} 、 \mathrm{Cu} 、 \mathrm{As} 、 \mathrm{Mo} 、 \mathrm{Cd} 、 \mathrm{Sb} 、 \mathrm{Tl} 、 \mathrm{~Pb}$ 的平均浓度低于世界卫生 组织 ( WHO) 饮用水质准则和中国 III 类地表水环境质量标准 (表 1). 但 $\mathrm{Al}$ 和 $\mathrm{As}$ 分别有 1 和 6 个采样点超出 了世界卫生组织饮用水质准则, 超标率分别为 $1.35 \%$ 和 $8.10 \% ; \mathrm{Fe} 、 \mathrm{Mn}$ 和 $\mathrm{Tl}$ 有 $16 、 3$ 和 3 个采样点超出了中 国 III 类地表水环境质量标准, 超标率分别为 $21.60 \% 、 4.05 \%$ 和 4.05\%. 本次研究发现赣江水系 $\mathrm{Cd}$ 浓度在水 质标准内, 与张宝军等 ${ }^{[12]} 2013$ 年的研究结果一致, 与计勇等 ${ }^{\left[{ }^{[13]}\right.} 2010$ 年的分析结果中 $\mathrm{Cd}$ 浓度在赣江贑州市 段超标不一致; As 浓度在中国 III 类地表水环境质量标准内, 与计勇等 ${ }^{[13]} 2010$ 年的分析结果中 As 在赣江赣 州市段与赣江吉安市段超出了中国 III类地表水环境质量标准不一致, 说明近年来 $\mathrm{Cd}$ 和 $\mathrm{As}$ 污染已明显减轻.

表 1 赣江水系溶解态金属元素的统计特征和水质标准 *

Tab.1 Statistics of dissolved metal concentrations in the Ganjiang River and the water standards

\begin{tabular}{|c|c|c|c|c|c|c|c|c|c|c|c|}
\hline \multirow{2}{*}{ 元素 } & \multicolumn{4}{|c|}{ 丰水期 $(n=37)$} & \multicolumn{4}{|c|}{ 枯水期 $(n=37)$} & \multirow{2}{*}{$\begin{array}{c}\text { 丰水期、 } \\
\text { 枯水期差 } \\
\text { 异显著 } \\
\text { 性 } P \text { 值 }\end{array}$} & \multicolumn{2}{|c|}{$\begin{array}{c}\text { 水质标准/ } \\
(\mu \mathrm{g} / \mathrm{L})\end{array}$} \\
\hline & $\begin{array}{c}\text { 最小值/ } \\
(\mu \mathrm{g} / \mathrm{L})\end{array}$ & $\begin{array}{c}\text { 最大值/ } \\
(\mu \mathrm{g} / \mathrm{L})\end{array}$ & $\begin{array}{l}\text { 平均值/ } \\
(\mu \mathrm{g} / \mathrm{L})\end{array}$ & $\begin{array}{l}\text { 标准差/ } \\
(\mu \mathrm{g} / \mathrm{L})\end{array}$ & $\begin{array}{c}\text { 最小值/ } \\
(\mu \mathrm{g} / \mathrm{L})\end{array}$ & $\begin{array}{c}\text { 最大值/ } \\
(\mu \mathrm{g} / \mathrm{L})\end{array}$ & $\begin{array}{l}\text { 平均值/ } \\
(\mu \mathrm{g} / \mathrm{L})\end{array}$ & $\begin{array}{l}\text { 标准差/ } \\
(\mu \mathrm{g} / \mathrm{L})\end{array}$ & & $\mathrm{WHO}^{\mathrm{a}}$ & 中国 ${ }^{b}$ \\
\hline $\mathrm{Be}$ & 0.001 & 0.072 & 0.007 & 0.013 & 0.001 & 0.168 & 0.031 & 0.033 & $<0.001$ & - & 2 \\
\hline $\mathrm{Al}$ & 6.037 & 24.340 & 11.490 & 3.676 & 18.870 & 989.700 & 186.900 & 186.200 & $<0.001$ & 900 & - \\
\hline $\mathrm{V}$ & 0.221 & 2.115 & 0.814 & 0.463 & 0.346 & 3.971 & 1.231 & 0.780 & 0.007 & - & 50 \\
\hline $\mathrm{Mn}$ & 0.906 & 220.2 & 17.18 & 37.37 & 4.331 & 216.4 & 31.72 & 39.02 & 0.106 & - & 100 \\
\hline $\mathrm{Fe}$ & 53.2 & 269.4 & 106.1 & 50.42 & 153.2 & 1918.0 & 336.2 & 295.8 & $<0.001$ & - & 300 \\
\hline Co & 0.039 & 0.229 & 0.084 & 0.046 & 0.088 & 0.543 & 0.234 & 0.112 & $<0.001$ & - & 1000 \\
\hline $\mathrm{Ni}$ & 0.506 & 3.890 & 1.364 & 0.750 & 0.771 & 8.110 & 2.197 & 1.865 & 0.014 & 70 & 20 \\
\hline $\mathrm{Cu}$ & 0.960 & 5.212 & 1.986 & 1.042 & 1.373 & 22.13 & 4.118 & 4.571 & 0.007 & 2000 & 1000 \\
\hline As & 0.262 & 36.090 & 2.986 & 6.066 & 0.392 & 97.890 & 8.240 & 19.500 & 0.122 & 10 & 50 \\
\hline Mo & 0.084 & 17.760 & 1.969 & 3.807 & 0.131 & 28.910 & 3.717 & 6.627 & 0.168 & - & 70 \\
\hline $\mathrm{Cd}$ & 0.002 & 1.874 & 0.135 & 0.320 & 0.013 & 2.665 & 0.282 & 0.528 & 0.150 & 3 & 5 \\
\hline $\mathrm{Sb}$ & 0.042 & 4.393 & 0.278 & 0.700 & 0.071 & 0.808 & 0.277 & 0.169 & 0.999 & 20 & 5 \\
\hline $\mathrm{Tl}$ & 0.011 & 0.162 & 0.042 & 0.031 & 0.011 & 0.127 & 0.047 & 0.027 & 0.494 & - & 0.1 \\
\hline $\mathrm{Pb}$ & 0.181 & 3.250 & 0.674 & 0.694 & 0.293 & 3.636 & 0.987 & 0.759 & 0.068 & 10 & 50 \\
\hline $\mathrm{U}$ & 0.012 & 0.376 & 0.083 & 0.098 & 0.047 & 0.999 & 0.367 & 0.238 & $<0.001$ & 30 & - \\
\hline
\end{tabular}

* $n$ 代表采样点数量, 一表示无数据. $\mathrm{a}$ 是世界卫生组织饮用水质准则 ${ }^{[26]}, \mathrm{b}$ 是中国 III 类地表水环境质量标准 ${ }^{[27]}$.

赣江溶解态金属元素浓度大小排序为: $\mathrm{Fe}>\mathrm{Al}>\mathrm{Mn}>\mathrm{As}>\mathrm{Cu}>\mathrm{Mo}>\mathrm{Ni}>\mathrm{V}>\mathrm{Pb}>\mathrm{Sb}>\mathrm{U}>\mathrm{Cd}>\mathrm{Co}>\mathrm{Tl}>\mathrm{Be} . \mathrm{Fe} 、 \mathrm{Al} 、 \mathrm{Mn}$ 的平均浓度分别是印度苏伯尔讷雷卡河的 1.6、1.5 和 2 倍, 其中 $\mathrm{Fe}$ 的平均浓度是汉江的 7 倍、渭河的 20 倍. $\mathrm{Co} 、 \mathrm{Ni} 、 \mathrm{Cu} 、 \mathrm{As} 、 \mathrm{Cd} 、 \mathrm{~Pb}$ 的平均浓度低于乐安河、长江、湘江、㴒河、多瑙河. Mo 和 $\mathrm{Sb}$ 的平均浓度分别低于渭河 和汉江, 可知赣江流域的 $\mathrm{Fe} 、 \mathrm{Al} 、 \mathrm{Mn}$ 浓度较高, $\mathrm{Co} 、 \mathrm{Ni} 、 \mathrm{Cu} 、 \mathrm{As} 、 \mathrm{Mo} 、 \mathrm{Cd} 、 \mathrm{Sb} 、 \mathrm{~Pb}$ 浓度较低(表 2).

$\mathrm{Be} 、 \mathrm{Al} 、 \mathrm{Mn} 、 \mathrm{~Pb} 、 \mathrm{U}$ 浓度在上游、中游、下游存在显著差异, 其他元素差异不显著. Ni 和 Mo 浓度在干流与 支流间存在显著差异, 其他元素差异不显著. $\mathrm{Be} 、 \mathrm{Al}$ 浓度在上游显著高于中下游, $\mathrm{Be} 、 \mathrm{Al} 、 \mathrm{Cu} 、 \mathrm{Co}$ 浓度在湘水、 章水和赣江赣州市段高, $\mathrm{Cu}$ 和 Co 浓度分别在中游河段蜀水和孤江浓度高, 在其他采样点浓度较低. As、 Mo、Sb 浓度在章水出现峰值, 其中 As 浓度在赣江赣州市段出现最大值, 其他采样点较低. Mn、Pb、U 浓度在 下游显著高于中上游, 在章水出现峰值, 其中 $\mathrm{Mn}$ 浓度在桃江出现最大值, 在中游降低, 在下游袁水、锦江增 加, 在赣江北支浓度最高. $\mathrm{Ni} 、 \mathrm{Cd} 、 \mathrm{Tl}$ 浓度在桃江、章水、赣江万安县段、赣江泰和县段、袁河较高, 其他采样点 较低. $\mathrm{V} 、 \mathrm{Fe}$ 浓度在支流高于干流, 分别在蜀水、泷江出现最大值, 在湘水的浓度高于多数河段 (表 3 和图 2). 
表 2 国内外河流溶解态金属元素研究结果 $(\mu \mathrm{g} / \mathrm{L}) *$

Tab.2 Dissolved metals in domestic and oversea rivers

\begin{tabular}{|c|c|c|c|c|c|c|c|c|c|c|}
\hline 元素 & 赣江 & $\begin{array}{l}\text { 乐安 } \\
\text { 河 }^{[28]}\end{array}$ & 长江 $^{[29]}$ & 湘江 $^{[30]}$ & 汉江 ${ }^{[31]}$ & 渭河 ${ }^{[32]}$ & 㴒河 [33] & $\begin{array}{l}\text { 苏伯尔讷 } \\
\text { 雷卡河 }{ }^{[34]}\end{array}$ & $\begin{array}{l}\text { Korotoa } \\
\text { 河 }^{[35]}\end{array}$ & $\begin{array}{l}\text { 多瑙 } \\
\text { 河 }^{[36]}\end{array}$ \\
\hline $\mathrm{Be}$ & 0.019 & - & - & - & - & - & - & - & - & - \\
\hline $\mathrm{Al}$ & 99.21 & - & 974.0 & - & 188.0 & - & - & 64.3 & - & - \\
\hline V & 1.023 & - & - & - & 69.9 & 68.0 & - & 14.1 & - & - \\
\hline $\mathrm{Mn}$ & 24.45 & - & - & - & 30.7 & 64.0 & - & 12.0 & - & 170.0 \\
\hline $\mathrm{Fe}$ & 221.1 & - & 1660 & - & 30.6 & 11.0 & - & 133.8 & - & - \\
\hline Co & 0.159 & - & 1.55 & - & 2.24 & - & - & 0.57 & - & - \\
\hline $\mathrm{Ni}$ & 1.780 & - & 3.69 & - & 1.71 & 1.0 & 5.43 & 25.2 & 32.0 & 2.89 \\
\hline $\mathrm{Cu}$ & 3.052 & 11.0 & 8.40 & 20.33 & 13.4 & - & 10.7 & 16.6 & 61.0 & 15.9 \\
\hline As & 5.613 & - & 7.040 & 12.24 & 14.2 & - & - & 5.41 & 37.0 & 2.54 \\
\hline Mo & 2.843 & - & - & - & - & 22.0 & - & - & - & - \\
\hline $\mathrm{Cd}$ & 0.208 & - & 0.280 & 1.34 & 2.31 & 0.02 & 0.92 & - & 8.0 & 0.12 \\
\hline $\mathrm{Sb}$ & 0.277 & - & - & - & 41.6 & - & - & - & - & - \\
\hline $\mathrm{Tl}$ & 0.045 & - & - & - & - & - & - & - & - & - \\
\hline $\mathrm{Pb}$ & 0.830 & 10.0 & 6.40 & 2.29 & 9.26 & - & 9.30 & - & 27.0 & 1.05 \\
\hline $\mathrm{U}$ & 0.225 & - & - & - & - & - & - & - & - & - \\
\hline
\end{tabular}

* “一”表示未检测, 赣江是本次研究的结果.

表 3 竷江水系不同河段的溶解态金属元素浓度 *

Tab.3 Concentrations of dissolved metals in different reaches of the Ganjiang River

\begin{tabular}{|c|c|c|c|c|c|c|c|c|c|c|c|c|}
\hline \multirow[b]{2}{*}{ 元素 } & \multicolumn{2}{|c|}{ 上游 $(n=32)$} & \multicolumn{2}{|c|}{ 中游 $(n=22)$} & \multicolumn{2}{|c|}{ 下游 $(n=20)$} & \multirow{2}{*}{$\begin{array}{l}P^{1} \\
\text { 值 }\end{array}$} & \multicolumn{2}{|c|}{ 干流 $(n=28)$} & \multicolumn{2}{|c|}{ 支流 $(n=46)$} & \multirow{2}{*}{$\begin{array}{l}P^{2} \\
\text { 值 }\end{array}$} \\
\hline & $\begin{array}{l}\text { 平均值/ } \\
(\mu \mathrm{g} / \mathrm{L})\end{array}$ & $\begin{array}{l}\text { 标准差/ } \\
(\mu \mathrm{g} / \mathrm{L})\end{array}$ & $\begin{array}{l}\text { 平均值/ } \\
(\mu \mathrm{g} / \mathrm{L})\end{array}$ & $\begin{array}{l}\text { 标准差/ } \\
(\mu \mathrm{g} / \mathrm{L})\end{array}$ & $\begin{array}{l}\text { 平均值/ } \\
(\mu \mathrm{g} / \mathrm{L})\end{array}$ & $\begin{array}{l}\text { 标准差/ } \\
(\mu \mathrm{g} / \mathrm{L})\end{array}$ & & $\begin{array}{l}\text { 平均值/ } \\
(\mu \mathrm{g} / \mathrm{L})\end{array}$ & $\begin{array}{l}\text { 标准差/ } \\
(\mu \mathrm{g} / \mathrm{L})\end{array}$ & $\begin{array}{l}\text { 平均值/ } \\
(\mu \mathrm{g} / \mathrm{L})\end{array}$ & $\begin{array}{l}\text { 标准差/ } \\
(\mu \mathrm{g} / \mathrm{L})\end{array}$ & \\
\hline $\mathrm{Be}$ & $0.035^{\mathrm{a}}$ & 0.036 & $0.008^{b}$ & 0.007 & $0.008^{\mathrm{b}}$ & 0.009 & 0.000 & 0.016 & 0.019 & 0.022 & 0.032 & 0.599 \\
\hline $\mathrm{Al}$ & $157.90^{\mathrm{a}}$ & 214.10 & $41.55^{\mathrm{b}}$ & 44.77 & $68.78^{\mathrm{b}}$ & 89.77 & 0.015 & 86.76 & 119.90 & 106.80 & 177.80 & 0.645 \\
\hline $\mathrm{V}$ & 0.923 & 0.495 & 1.044 & 0.971 & 1.158 & 0.502 & 0.469 & 0.954 & 0.598 & 1.064 & 0.715 & 0.945 \\
\hline $\mathrm{Mn}$ & $29.13^{\mathrm{ab}}$ & 41.23 & $8.39^{\mathrm{b}}$ & 5.708 & $34.63^{\mathrm{a}}$ & 49.80 & 0.047 & 23.47 & 42.91 & 25.04 & 36.27 & 0.808 \\
\hline $\mathrm{Fe}$ & 211.0 & 162.1 & & 384.9 & 244.3 & 121.5 & 0.882 & 178.6 & 116.7 & 247.0 & 289.5 & 0.206 \\
\hline Co & 0.171 & 0.135 & 0.125 & 0.091 & 0.176 & 92 & 0.252 & 0.159 & 0.124 & 0.159 & 0.108 & 0.906 \\
\hline $\mathrm{Ni}$ & 1.372 & 0.765 & 1.903 & 57 & 2.298 & 27 & 0.077 & 2.159 & & 1.550 & 16 & 0.044 \\
\hline $\mathrm{Cu}$ & 3.831 & 4.080 & 2.636 & 3.833 & 2.262 & 0.894 & 0.228 & 2.709 & 1.397 & 3.260 & 4.262 & 0.313 \\
\hline As & 9.544 & 21.620 & 2.525 & 2.257 & 2.719 & 1.631 & 0.128 & 5.843 & 18.160 & 5.473 & 12.130 & 0.312 \\
\hline Mo & 4.389 & 7.646 & & 2.950 & 1.463 & 1.213 & 0.099 & 2.435 & 2.603 & 3.091 & 6.614 & 0.003 \\
\hline $\mathrm{Cd}$ & 0.175 & 0.348 & 0.228 & 0.426 & 0.239 & 0.586 & 0.854 & 0.202 & 0.387 & 0.212 & 0.474 & 0.813 \\
\hline $\mathrm{Sb}$ & 0.371 & 0.760 & 0.164 & 0.073 & 0.252 & 0.078 & 0.330 & 0.209 & 0.102 & 0.319 & 0.636 & 0.829 \\
\hline $\mathrm{Tl}$ & 0.047 & 0.030 & 0.035 & 0.026 & 0.056 & 0.029 & 0.145 & 0.044 & 0.021 & 0.045 & 0.033 & 0.150 \\
\hline $\mathrm{Pb}$ & $0.942^{\mathrm{a}}$ & 0.783 & $0.480^{\mathrm{b}}$ & 0.265 & $1.039^{\mathrm{a}}$ & 0.903 & 0.024 & 0.686 & 0.608 & 0.919 & 0.803 & 0.069 \\
\hline $\mathrm{U}$ & $0.247^{\mathrm{ab}}$ & 0.262 & $0.123^{b}$ & 0.136 & $0.304^{\mathrm{a}}$ & 0.228 & 0.029 & 0.185 & 0.190 & 0.250 & 0.251 & 0.206 \\
\hline
\end{tabular}

* $n$ 为样点数量,上标不同小写字母代表在 0.05 显著性水平检验时,统计集群之间存在显著差异, $P^{1}$ 表示上中下游河段 差异显著性 $P$ 值, $P^{2}$ 表示干流与支流河段差异显著性 $P$ 值. 

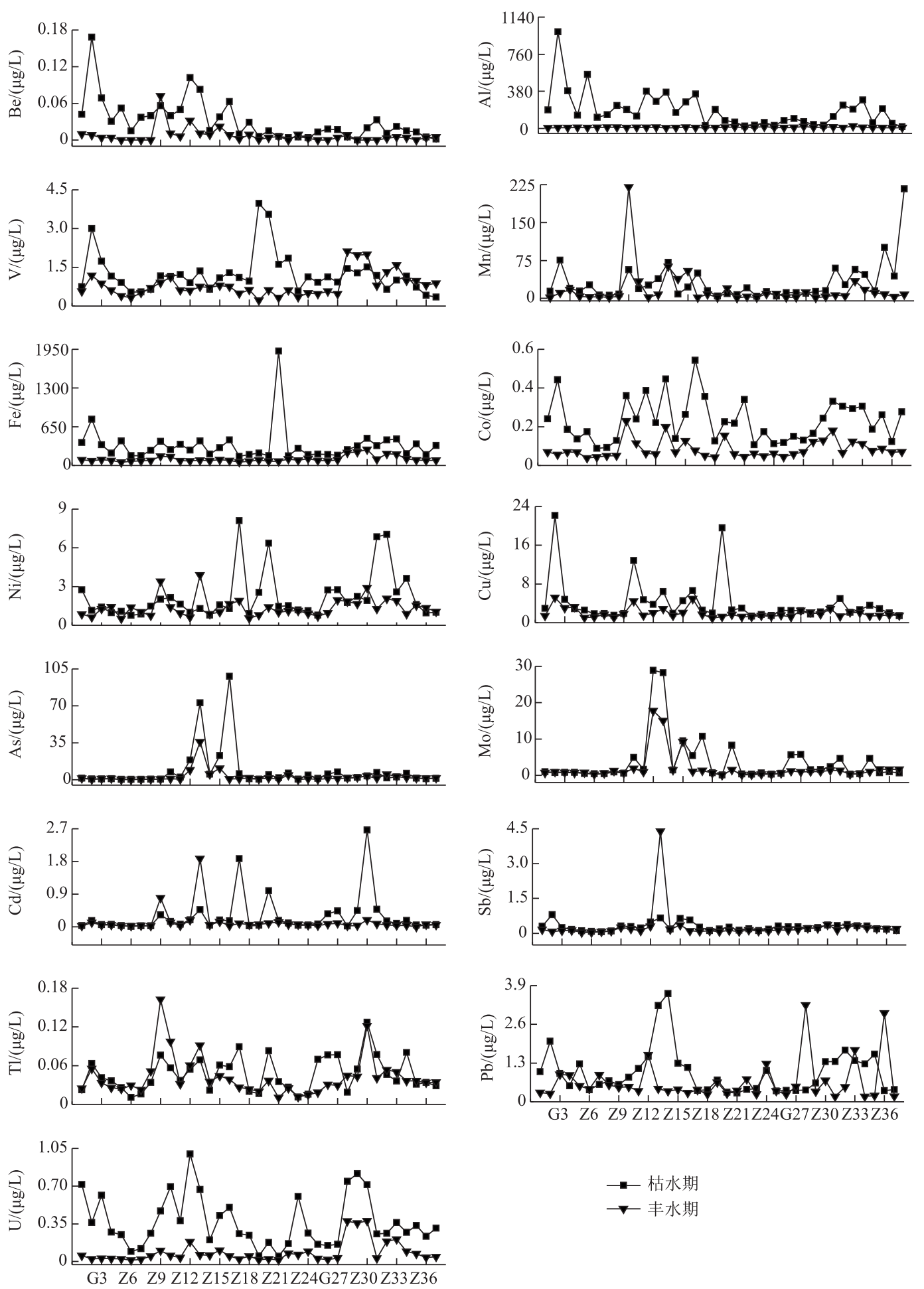

$$
\begin{aligned}
& \text { — 枯水期 } \\
& \text { - } \text { 丰水期 }
\end{aligned}
$$

图 2 赣江水系溶解态金属元素的时空分布

Fig.2 Spatio-temporal distribution of dissolved metals in the Ganjiang River 


\section{2 溶解态金属元素污染来源识别}

为验证因子分析的适用性, 对数据进行 KMO (Kaiser-Meyer-Olkin) 和巴特利特球形度检验,一般认 为 $\mathrm{KMO}>0.7$ 时适合因子分析. 通过检验发现, 在 $P<$ 0.001 时 KMO 值为 0.837 , 球形度检验值为 869.42 , 表 明采用主成分分析是有效的. 3 个主成分反映了 $69.82 \%$ 的变量信息,揭示了 15 种金属元素可能存在 的 3 种来源 (表 4$)$.

$\mathrm{PC} 1$ 解释了 $30.55 \%$ 的方差变异, $\mathrm{Be} 、 \mathrm{Al} 、 \mathrm{Fe} 、 \mathrm{Co} 、 \mathrm{U}$ 占有较高的正载荷 (本研究中以 $R>0.7$ 判定为载荷较 高 $\left.^{[37]}\right), \mathrm{Mn} 、 \mathrm{Cu}$ 和 $\mathrm{Pb}$ 具有较低载荷. 桃江、湘水和章 水流域 $\mathrm{Mn}, \mathrm{Be} 、 \mathrm{Al} 、 \mathrm{Cu}$ 和 $\mathrm{Pb} 、 \mathrm{U}$ 浓度分别出现最大值. 锡矿 ${ }^{[38]}$ 和铇矿 ${ }^{[39]}$ 中含有 $\mathrm{Be} 、 \mathrm{Al} 、 \mathrm{Fe} 、 \mathrm{~Pb} 、 \mathrm{Co}$ 元素, 桃 江、湘水和章水流域分别是稀土矿 ${ }^{[40]}$ 、锡矿、铇矿开采 频繁的河段 (见赣州市环境信息发布平台 http: // www. gzhb. gov. cn/infopublic/flexoutput/), 采矿废水排放人 河,导致该区域 $\mathrm{Mn} 、 \mathrm{Be} 、 \mathrm{Al} 、 \mathrm{Cu} 、 \mathrm{~Pb} 、 \mathrm{U}$ 浓度增加. $\mathrm{Be} 、$ $\mathrm{Al} 、 \mathrm{Fe} 、 \mathrm{Co} 、 \mathrm{U} 、 \mathrm{Cu}$ 浓度在枯水期显著高于丰水期 (表 1 和图 2), 体现了丰水期降水对采矿废水的稀释作用. PC1 表示溶解态金属元素的采矿废水来源.

PC2 解释了 $22.61 \%$ 的方差变异, Mo 在该成分的 载荷最高, 其次为 $\mathrm{As} 、 \mathrm{Tl} 、 \mathrm{Sb}$ 和 $\mathrm{Cd} . \mathrm{Tl}$ 和 $\mathrm{As} 、 \mathrm{Mo} 、 \mathrm{Sb}$ 分 别在桃江和章水出现峰值. 矿产废渣中含有丰富的
表 4 赣江水系溶解态金属元素主成分旋转载荷 *

Tab.4 Rotating loadings of dissolved metals on principal components in the Ganjiang River

\begin{tabular}{cccc}
\hline 元素 & PC1 & PC2 & PC3 \\
\hline $\mathrm{Be}$ & 0.777 & 0.347 & -0.062 \\
$\mathrm{Al}$ & 0.896 & -0.015 & 0.167 \\
$\mathrm{~V}$ & 0.282 & 0.263 & 0.684 \\
$\mathrm{Mn}$ & 0.585 & 0.306 & 0.228 \\
$\mathrm{Fe}$ & 0.799 & -0.001 & 0.510 \\
$\mathrm{Co}$ & 0.726 & 0.268 & 0.542 \\
$\mathrm{Ni}$ & 0.119 & 0.265 & 0.803 \\
$\mathrm{Cu}$ & 0.575 & 0.338 & 0.397 \\
$\mathrm{As}$ & 0.200 & 0.751 & 0.216 \\
$\mathrm{Mo}$ & 0.132 & 0.871 & -0.068 \\
$\mathrm{Cd}$ & 0.144 & 0.668 & 0.318 \\
$\mathrm{Sb}$ & 0.383 & 0.685 & 0.412 \\
$\mathrm{Tl}$ & 0.061 & 0.745 & 0.427 \\
$\mathrm{~Pb}$ & 0.648 & 0.088 & 0.005 \\
$\mathrm{U}$ & 0.772 & 0.227 & 0.297 \\
特征值 & 4.58 & 3.39 & 2.50 \\
方差贡献率/\% & 30.55 & 22.61 & 16.66 \\
累积方差贡献率/\% & 30.55 & 53.16 & 69.82 \\
\hline
\end{tabular}

* KMO 检验值为 0.837 , Bartlett 球形度检验相伴概率 $<0.001$.

$\mathrm{As} 、 \mathrm{Sb} 、 \mathrm{Cd}$ 元素 ${ }^{[41-42]}$, 施用化肥农药也会导致 $\mathrm{As}$ 和 $\mathrm{Cd}$ 残留于土壤中 ${ }^{[43]}$, 桃江和章水流域的稀土和铇矿分布 广泛 (图 1), 同时也是农业种植区和脐橙种植区, 降雨淋滤把矿渣和土壤中的 As、Sb、Cd 带人河流, 导致 As、 $\mathrm{Sb} 、 \mathrm{Cd}$ 浓度在该区域出现最大值. As、Mo、Cd、Sb、Tl 浓度在丰水期和枯水期不存在显著差异, 体现了长期受 降水淋滤的影响. PC2 表示溶解态金属元素的矿渣和农田土壤降雨淋滤来源.

$\mathrm{PC} 3$ 解释了 $16.66 \%$ 的方差变异, $\mathrm{Ni}$ 在该成分上占有的载荷最高, 其次为 $\mathrm{V} ; \mathrm{Fe} 、 \mathrm{Co} 、 \mathrm{Sb}$ 和 $\mathrm{Tl}$ 与 PC3 具有 相近的载荷. Ni、Co 浓度分别在赣江万安县段、赣江赣州市段出现最大值; 对比 3 个区域污染水平, $\mathrm{Ni}$ 和 $\mathrm{V}$ 浓度在 $\mathrm{C} 2$ 最高 (表 4) , $\mathrm{V} 、 \mathrm{Ni} 、 \mathrm{Fe}$ 和 $\mathrm{Co}$ 的平均浓度在枯水期显著高于丰水期 (表 1). 钢铁冶炼废水中含有大 量 $\mathrm{Ni} 、 \mathrm{Fe} 、 \mathrm{Co}^{[44]}$ 和 $\mathrm{V}^{[45]}$ 元素, 袁水、锦江流域煤矿、铁矿资源分布广泛 (图 1), 受钢铁冶炼废水排放影响, 该 区域 $\mathrm{Ni} 、 \mathrm{Fe} 、 \mathrm{Co}$ 浓度出现最大值. PC3 表示溶解态金属元素的钢铁冶炼废水来源.

\section{3 溶解态金属元素区域污染差异}

根据各样点溶解态金属元素浓度的空间差异 (图 2), 再根据不同样点的层次聚类分析结果 (图 3), 赣江 水系溶解态金属元素可以分为 3 个污染区域. $13.5 \%$ 的样点在区域 $1(\mathrm{C} 1)$, 分布在湘水、章水和贑江贑州市 段; 16.2\% 的采样点在区域 2(C2), 分布在桃江、袁水和锦江; 70.3\% 的采样点在区域 3(C3) (图 1 和图 3). 据 表 5 可知,除 $\mathrm{Mn} 、 \mathrm{Fe} 、 \mathrm{Cd} 、 \mathrm{~Pb}$ 在 3 个区域中差异不显著外, 其他元素差异显著. $\mathrm{Be} 、 \mathrm{Al} 、 \mathrm{Cu} 、 \mathrm{As} 、 \mathrm{Mo} 、 \mathrm{Sb}$ 的平均 浓度在 $\mathrm{C} 1$ 最高; $\mathrm{V} 、 \mathrm{Mn} 、 \mathrm{Fe} 、 \mathrm{Ni} 、 \mathrm{Cd}$ 的平均浓度在 $\mathrm{C} 2$ 最高; $\mathrm{C} 3$ 除 $\mathrm{Ni} 、 \mathrm{Cu} 、 \mathrm{Mo}$ 外, 其他元素的平均浓度显著低 于 $\mathrm{C} 1$ 和 $\mathrm{C} 2.3$ 个区域元素的污染水平大小排序为: $\mathrm{C} 1>\mathrm{C} 2>\mathrm{C} 3$. C1 是赣南矿产集中分布区, 同时是我国重要 的脐橙种植区, 受采矿废水排放、矿渣和土壤降雨淋滤影响, Be、Al、Cu、As、Mo、Sb 浓度最高. C2 是铁矿、煤 矿集中分布区, 受沿岸钢铁冶炼废水排放的影响, $\mathrm{V} 、 \mathrm{Mn} 、 \mathrm{Fe} 、 \mathrm{Ni} 、 \mathrm{Cd}$ 浓度最高. C3 的支流河段采矿和农业活 动少于 $\mathrm{C} 1$ 和 $\mathrm{C} 2$, 同时 $\mathrm{C} 3$ 包括了大部分干流, 因支流汇人导致径流量增加, 从而稀释了部分溶解态金属元 素,使溶解态金属元素浓度低于 $\mathrm{C} 1$ 和 $\mathrm{C} 2$. 


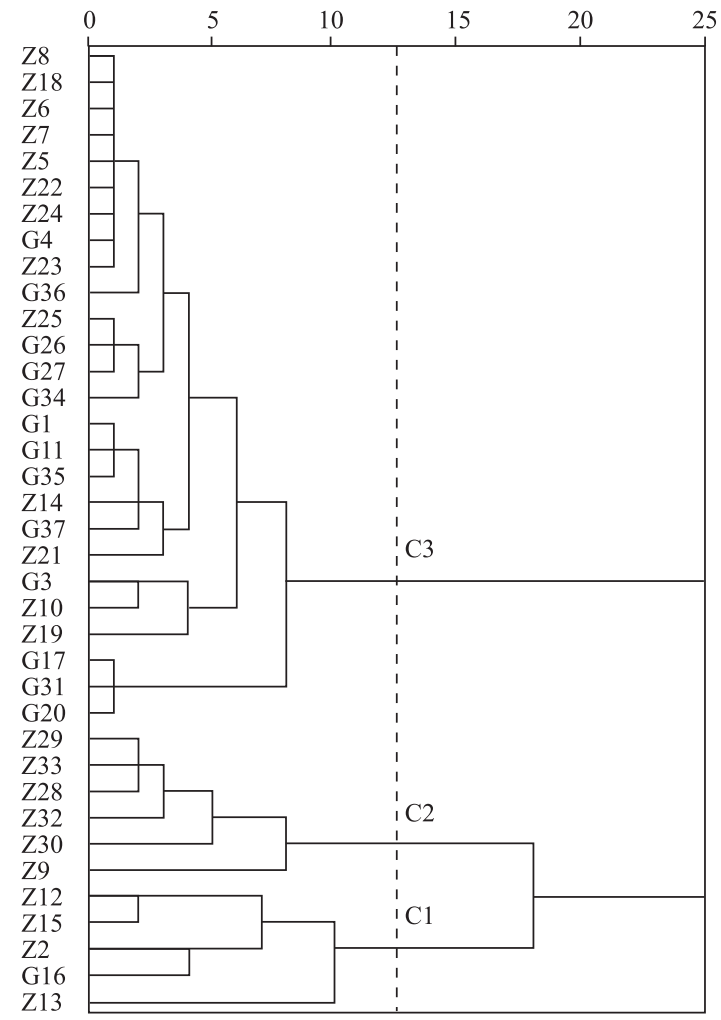

图 3 赣江水系溶解态金属元素聚类分析树形图

Fig.3 Hierarchical cluster tree of sampling sites by Cluster Analysis of dissolved metals in the Ganjiang River

表 5 赣江水系各区域溶解态金属元素平均值和标准误差 $*$

Tab.5 Mean values with standard errors of dissolved metals in different regions in the Ganjiang River

\begin{tabular}{|c|c|c|c|c|c|c|}
\hline \multirow{2}{*}{ 元素 } & \multicolumn{2}{|c|}{ C1 } & \multicolumn{2}{|c|}{$\mathrm{C} 2$} & \multicolumn{2}{|c|}{$\mathrm{C} 3$} \\
\hline & 平均值 $/(\mu \mathrm{g} / \mathrm{L})$ & 标准误/ $(\mu \mathrm{g} / \mathrm{L})$ & 平均值 $/(\mu \mathrm{g} / \mathrm{L})$ & 标准误 $/(\mu \mathrm{g} / \mathrm{L})$ & 平均值 $/(\mu \mathrm{g} / \mathrm{L})$ & 标准误/ $(\mu \mathrm{g} / \mathrm{L})$ \\
\hline $\mathrm{Be}$ & $0.054^{\mathrm{a}}$ & 0.016 & $0.017^{\mathrm{b}}$ & 0.007 & $0.013^{\mathrm{b}}$ & 0.002 \\
\hline $\mathrm{Al}$ & $231.60^{\mathrm{a}}$ & 97.65 & $80.90^{\mathrm{b}}$ & 28.00 & $77.98^{\mathrm{b}}$ & 15.71 \\
\hline $\mathrm{V}$ & $1.173^{\mathrm{ab}}$ & 0.219 & $1.411^{\mathrm{a}}$ & 0.132 & $0.904^{\mathrm{b}}$ & 0.094 \\
\hline Mn & 39.56 & 8.64 & 44.35 & 17.22 & 16.95 & 4.48 \\
\hline $\mathrm{Fe}$ & 258.97 & 72.38 & 297.70 & 31.50 & 196.20 & 36.33 \\
\hline Co & $0.243^{\mathrm{a}}$ & 0.056 & $0.216^{\mathrm{a}}$ & 0.026 & $0.129^{b}$ & 0.012 \\
\hline $\mathrm{Ni}$ & $1.412^{\mathrm{b}}$ & 0.296 & $2.606^{\mathrm{a}}$ & 0.429 & $1.660^{\mathrm{ab}}$ & 0.209 \\
\hline $\mathrm{Cu}$ & $6.064^{\mathrm{a}}$ & 1.857 & $2.221^{\mathrm{b}}$ & 0.122 & $2.664^{\mathrm{b}}$ & 0.415 \\
\hline As & $27.10^{\mathrm{a}}$ & 10.50 & $2.50^{\mathrm{b}}$ & 0.38 & $2.20^{\mathrm{b}}$ & 0.30 \\
\hline Mo & $11.694^{\mathrm{a}}$ & 3.361 & $0.970^{\mathrm{b}}$ & 0.185 & $1.573^{\mathrm{b}}$ & 0.294 \\
\hline $\mathrm{Cd}$ & 0.353 & 0.173 & 0.404 & 0.216 & 0.135 & 0.041 \\
\hline $\mathrm{Sb}$ & $0.840^{\mathrm{a}}$ & 0.402 & $0.291^{\mathrm{b}}$ & 0.018 & $0.166^{\mathrm{b}}$ & 0.011 \\
\hline $\mathrm{Tl}$ & $0.059^{\mathrm{a}}$ & 0.004 & $0.070^{\mathrm{a}}$ & 0.013 & $0.036^{\mathrm{b}}$ & 0.003 \\
\hline $\mathrm{Pb}$ & 1.226 & 0.297 & 1.092 & 0.247 & 0.694 & 0.088 \\
\hline $\mathrm{U}$ & $0.338^{\mathrm{a}}$ & 0.101 & $0.414^{\mathrm{a}}$ & 0.067 & $0.160^{\mathrm{b}}$ & 0.025 \\
\hline
\end{tabular}

* C1 : 湘水、章水、赣江赣州市段; C2 : 桃江、袁水、锦江; C3 : 其他区域. 上标不同小写字母表示在 $P<0.05$ 显著性水平时,统 计集群之间存在显著差异. 


\section{4 溶解态金属元素污染来源贡献率}

在主成分分析识别赣江水系溶解态金属元素污 染来源基础上,用绝对主成分/多元线性回归(MLRAPCS) 计算了赣江水体 15 种溶解态金属元素的污染 源贡献率. 除 $\mathrm{Mn} 、 \mathrm{Fe} 、 \mathrm{~Pb} 、 \mathrm{U}$ 的 $R^{2}$ 小于 0.6 外,其他元 素都在 0.6 以上 (表 6 ), 说明回归分析具有统计学意 $义^{[46]} . \mathrm{Be} 、 \mathrm{Al} 、 \mathrm{Cu} 、 \mathrm{~Pb} 、 \mathrm{U}$ 的污染源超过 $40 \%$ 来自采矿 废水,其中 $\mathrm{Be} 、 \mathrm{Al} 、 \mathrm{U}$ 超过了 $70 \%, \mathrm{Mo}$ 的采矿废水贡 献率最低,其次为 $\mathrm{Co}$ 和 $\mathrm{Sb} . \mathrm{Cu} 、 \mathrm{As} 、 \mathrm{Mo} 、 \mathrm{Cd}$ 的污染源 超过 35\% 来自矿渣和农田土壤降雨淋滤, 其中 $\mathrm{Cu}$ 的 贡献率最大,其次为 $\mathrm{Cd}$ 和 $\mathrm{Mo}, \mathrm{Mn}$ 的矿渣和农田土 壤降雨淋滤贡献率最低, 其次为 $\mathrm{Al} 、 \mathrm{~V} 、 \mathrm{Ni} 、 \mathrm{Tl} 、 \mathrm{~Pb}$ 和 Fe. V、Mn、Co、 $\mathrm{Ni}$ 的污染源超过 $41 \%$ 来自钢铁冶炼废 水,其中 Mo 超过了 $60 \%, \mathrm{As}$ 的钢铁冶炼废水贡献率 最低,其次为 $\mathrm{Cu}$ 和 $\mathrm{Tl} . \mathrm{Fe}$ 的采矿废水和金属冶炼废 水贡献率都为 $35 \%$, 其来源可能主要受两者双重影 响. $\mathrm{V} 、 \mathrm{Fe} 、 \mathrm{Co} 、 \mathrm{Ni} 、 \mathrm{Cd} 、 \mathrm{Sb} 、 \mathrm{Tl} 、 \mathrm{~Pb}$ 除受已识别的 3 种源 影响外, 还受其他污染源的影响, 其中 $V 、 C o 、 A s 、 S b 、$ $\mathrm{Tl} 、 \mathrm{~Pb}$ 不可识别源的比例超过 $30 \%$.

\section{3 结论}

本次研究基于赣江流域枯水期和丰水期溶解态 金属元素的数据, 探讨溶解态金属元素的空间分布 特征、污染来源及污染来源的贡献率, 结果表明多数 水样的溶解态金属元素浓度符合水质标准,主要超 标元素(样品超标率) 为 $\mathrm{Fe}(21.60 \%) 、 \mathrm{As}(8.10 \%) 、 \mathrm{Mn}(4.05 \%) 、 \mathrm{Tl}(4.05 \%)$ 和 $\mathrm{Al}(1.35 \%)$. 赣江水系受溶解 态金属元素污染的主要河段为湘水、章水和赣江赣州市段,主要污染金属元素分别是 $\mathrm{Be} 、 \mathrm{Al} 、 \mathrm{Cu} 、 \mathrm{As} 、 \mathrm{Mo} 、 \mathrm{Sb}$; 其次为桃江、袁水和锦江, 主要污染金属元素分别是 $\mathrm{V} 、 \mathrm{Mn} 、 \mathrm{Fe} 、 \mathrm{Ni} 、 \mathrm{Cd}$. 采矿废水、矿渣和农田土壤降雨淋滤、 钢铁冶炼废水是赣江水系溶解态金属元素的主要来源. $\mathrm{Be} 、 \mathrm{Al} 、 \mathrm{Cu} 、 \mathrm{~Pb} 、 \mathrm{U}$ 的污染源超过 $40 \%$ 来自采矿废水; $\mathrm{Cu} 、 \mathrm{As} 、 \mathrm{Mo} 、 \mathrm{Cd}$ 的污染源超过 35\% 来自矿渣和农田土壤降雨淋滤; $\mathrm{V} 、 \mathrm{Mn} 、 \mathrm{Co} 、 \mathrm{Ni}$ 的污染源超过 $41 \%$ 来自钢铁 治炼废水. 赣江流域南部和西北部矿产资源的开采加工是赣江水体溶解态金属元素的主要污染源, 加强矿 区的环境保护和治理是防治赣江金属元素污染的关键.

\section{4 参考文献}

[ 1 ] Sin SN, Chua H, Lo W et al. Assessment of heavy metal cations in sediments of Shing Mun River, Hong Kong. Environment International, 2001, 26(5) : 297-301.

[ 2 ] Yuan G, Liu C, Chen L et al. Inputting history of heavy metals into the inland lake recorded in sediment profiles: Poyang Lake in China. Journal of hazardous materials, 2011, 185(1) : 336-345.

[ 3 ] Armitage PD, Bowes MJ, Vincent HM. Long-term changes in macroinvertebrate communities of a heavy metal polluted stream: The river Nent (Cumbria, UK) after 28 years. River Research and Applications, 2007, 23(9) : 997-1015.

[ 4 ] Bo L, Wang D, Li T et al. Accumulation and risk assessment of heavy metals in water, sediments, and aquatic organisms in rural rivers in the Taihu Lake region, China. Environmental Science and Pollution Research, $2015,22(9)$ : 6721.

[ 5 ] Palma P, Ledo L, Alvarenga P. Assessment of trace element pollution and its environmental risk to freshwater sediments influenced by anthropogenic contributions: The case study of Alqueva reservoir (Guadiana Basin). Catena, 2015, 128: 174-184. 
[6] Zhao SN, Shi XH, Li CY et al. Distribution characteristics of mercury and pollution risk assessment in the water of Lake Ulansuhai. J Lake Sci, 2014, 26(2):221-227. DOI: 10.18307/2014.0208. [赵胜男, 史小红, 李畅游等. 乌梁素海水 体录的分布特征及污染风险评估. 湖泊科学, 2014, 26(2): 221-227.]

[ 7 ] Licheng Z, Kezhun Z. Background values of trace elements in the source area of the Yangtze River. Science of the Total Environment, 1992, 125: 391-404.

[ 8 ] Dahlem Workshop on Changing Metal Cycles, Human Health ed. Changing metal cycles and human health: Report of the Dahlem Workshop on Changing Metal Cycles and. Springer-Verlag, 1984.

[ 9 ] Chapman DV ed. Water quality assessments: A guide to the use of biota, sediments, and water in environmental monitoring. London: CRC Press, 1996.

[10] Zhang DW, Zhang L, He JH et al. Spatial distributions and risk assessment of dissolved heavy metals in Poyang Lake. Acta Ecologica Sinica, 2015, 35(24) : 8028-8035. [张大文, 张莉, 何俊海等. 鄱阳湖溶解态重金属空间分布格局及风险 评估. 生态学报, 2015, 35(24) : 8028-8035.]

[11] Li WM, Yang ZF, Zhou L et al. Geochemical characteristic and fluxes of heavy metals in water system of the Poyang Lake. Geoscience, 2014, 28(3): 512-536. [李文明, 杨忠芳, 周雷等. 鄱阳湖水系重金属元素地球化学特征及人湖通量. 现代地质, 2014, 28(3): 512-536.]

[12] Zhang BJ, Zhu MN, Wang P et al. Spatial and temporal distribution of dissolved cadmium and water quality assessment of the water body of the Ganjiang River Catchment. Journal of Ecology and Rural Environment, 2014, 30(4) : 495-499. [张 宝军, 朱蒙曼, 王鹏等. 赣江流域水体中可溶态镉的时空分布特征及水质评价. 生态与农村环境学报, 2014,30 (4) : 495-499.]

[13] Ji Y, Zhang J, Fan HB et al. Distribution characteristics of heavy metal and environmental assessment in the mid-lower reaches of the Ganjiang River. China Rural Water and Hydropower, 2013, 4(5): 42-45. [计勇, 张洁, 㚞后保等. 赣江 中下游城市断面重金属分布特征及生态风险评价. 中国农村水利水电, 2013, 4(5): 42-45.]

[14] Ji Y, Zhang J, Huang X et al. Investigation and assessment of heavy metals in surface sediments of Ganjiang River, China. Journal of Environmental Biology, 2014, 35(6) : 1173-1179.

[15] Wang P, Chen DD, Chen B. The distribution characters and pollution sources of nitrogen and phosphorus nutrients in Ganjiang River. Journal of Jiangxi Normal University: Natural Science, 2015, 39(4) : 435-440. [王鹏, 陈多多, 陈波. 赣江 水体氮磷营养盐分布特征与污染来源. 江西师范大学学报: 自然科学版, 2015, 39(4) : 435-440.]

[16] Zhao ZG. Researches on development pattern of agriculture in the forest areas of Jiangxi Province based on land suitability evaluation. Hubei Agricultural Sciences, 2013,52(22) : 5634-5638. [ 赵志刚. 江西省林耕地适宜性评价与农业发展格 局探讨. 湖北农业科学, 2013, 52(22): 5634-5638.]

[17] Zhang CH. Statistical analysis of industrial agglomeration in Jiangxi Province. Times Finance, 2016, (17): 71-72. [张丛 煌. 江西省工业集聚情况统计分析. 时代金融, 2016, (17): 71-72.]

[18] Huang CG, Liu CG, Ding SH et al. Prediction type and characteristics of main mineral resources in Jiangxi Province. Resources Survey and Environment, 2015, 36(3): 196-202. [黄传冠, 刘春根, 丁少辉等. 江西省主要矿产预测类型及 其地质特征. 资源调查与环境, 2015, 36(3) : 196-202.]

[19] Compilation Committee of geological and mineral records of Jiangxi ed. Chronicles of Jiangxi Province 4. Beijing: China Local Records Publishing, 1998. [江西省地质矿产志编纂委员会编. 江西省志 4. 北京: 方志出版社, 1998. ]

[20] Li S, Gu S, Liu W et al. Water quality in relation to land use and land cover in the upper Han River Basin, China. Cate$n a, 2008, \mathbf{7 5}(2): 216-222$.

[21] Thurston GD, Spengler JD. A quantitative assessment of source contributions to inhalable particulate matter pollution in metropolitan Boston. Atmospheric Environment, 1985, 19(1) : 9-25.

[22] Gholizadeh MH, Melesse A, Reddi L. Water quality assessment and apportionment of pollution sources using APCS-MLR and PMF receptor modeling techniques in three major rivers of South Florida. Science of the total Environment, 2016, 566: 1552-1567.

[23] Nazeer S, Ali Z, Malik RN. Water quality assessment of River Soan (Pakistan) and source apportionment of pollution sources through receptor modeling. Archives of Environmental Contamination and Toxicology, 2016, 71(1) : 97-112.

[24] Su S L, Li D, Zhang Q et al. Temporal trend and source apportionment of water pollution in different functional zones of Qiantang River, China. Water Research, 2011, 45(4) : 1781-1795.

[25] Zhou F, Huang GH, Guo HC et al. Spatio-temporal patterns and source apportionment of coastal water pollution in eastern 
Hong Kong. Water Research, 2007, 41( 15 ) : 3429-3439.

[26] Organization WH ed. Guidelines for drinking-water quality: Recommendations. World Health Organization, 2004.

[27] State Environmental Protection Administration, General Administration of Quality Supervision, Inspection and Quarantine of the People's Republic of China eds. State Standard of the People's Republic of China GB 3838-2002, 2002. [ 国家环 境保护总局，国家质量监督检验检疫总局. 中华人民共和国国家标准 GB 3838-2002, 2002.]

[28] Wan JB, Yan WW, Xie T. Research on heavy metals pollution status of Le'an Rier, Lake Poyang Basin. J Lake Sci, 2007, 19(4) : 421-427. DOI: 10.18307/2007.0410. [万金保, 间伟伟, 谢婷. 鄱阳湖流域乐安河重金属污染水平. 湖泊科 学, 2007,19(4): 421-427.]

[29] Wang L, Wang Y, Xu C et al. Analysis and evaluation of the source of heavy metals in water of the River Changjiang. Environmental Monitoring and Assessment, 2011, 173(1/2/3/4): 301-313.

[30] Zeng X, Liu Y, You S et al. Spatial distribution, health risk assessment and statistical source identification of the trace elements in surface water from the Xiangjiang River, China. Environmental Science and Pollution Research, 2015, 22(12): 9400-9412.

[31] Li S, Zhang Q. Spatial characterization of dissolved trace elements and heavy metals in the upper Han River (China) using multivariate statistical techniques. Journal of Hazardous Materials, 2010, 176(1) : 579-588.

[32] Jing L, Fadong L, Qiang L et al. Spatial distribution and sources of dissolved trace metals in surface water of the Wei River, China. Water Science \& Technology, 2013, 67(4) : 817.

[33] Wang Z, Sun R, Zhang H et al. Analysis and assessment of heavy metal contamination in surface water and sediments: A case study from Luan River, Northern China. Frontiers of Environmental Science \& Engineering, 2015, 9(2) : 240-249.

[34] Giri S, Singh AK. Risk assessment, statistical source identification and seasonal fluctuation of dissolved metals in the Subarnarekha River, India. Journal of Hazardous Materials, 2014, 265: 305-314.

[35] Saiful IM, Kawser AM, Mohammad R et al. Heavy metal pollution in surface water and sediment: A preliminary assessment of an urban river in a developing country. Ecological Indicators, 2015, 48: 282-291.

[36] Dević G, Sakan S, Đorđević D. Assessment of the environmental significance of nutrients and heavy metal pollution in the river network of Serbia. Environmental Science and Pollution Research, 2016, 23(1) : 282-297.

[37] Simeonov V, Stratis JA, Samara C et al. Assessment of the surface water quality in Northern Greece. Water Research, 2003, 37(17): 4119-4124.

[38] Lu N. Comprehensive benefits of tin ores. Geology and Exploration, 1980, (4) : 43. [鲁宁. 锡矿石的综合利用. 地质勘 探, 1980, (4): 43.]

[39] Deng AT. Opinions on reserves calculation of associated beneficial components of tungsten ore in central south China. Geology and Exploration, 1957, (16) : 4-5. [邓安太. 对中南铇矿伴生有益组份储量计算的意见. 地质与勘探, 1957, (16) : 4-5.]

[40] Peng Y, He JG, Zhang ZM et al. Eco-environmental dynamic monitoring and assessment of rare earth mining area in southern Ganzhou using remote sensing. Acta Ecologica Sinica, 2016, 36(6) : 1676-1685. [彭燕, 何国金, 张兆明等. 赣南 稀土矿开发区生态环境遥感动态监测与评估. 生态学报, 2016, 36 (6) : 1676-1685.]

[41] Dudka S, Adriano DC. Environmental impacts of metal ore mining and processing: A review. Journal of Environmental Quality, 1997, 26(3) : 590-602.

[42] Wang F, Huang ZY, Wang XL et al. Ecological risk assessment of heavy metals in surrounding soils of tungsten ores: Comparison of different evaluation methods. Environmental Chemistry, 2015, 34(2): 225-233. [王斐, 黄益宗, 王小玲 等. 江西铇矿周边土壤重金属生态风险评价: 不同评价方法的比较. 环境化学, 2015, 34(2): 225-233.]

[43] Franklin RSCE, Duis L, Brown R et al. Trace element content of selected fertilizers and micronutrient source materials. Communications in Soil Science and Plant Analysis, 2005, 36(11/12) : 1591-1609.

[44] Krishna AK, Satyanarayanan M, Govil PK. Assessment of heavy metal pollution in water using multivariate statistical techniques in an industrial area: A case study from Patancheru, Medak District, Andhra Pradesh, India. Journal of Hazardous Materials, 2009, 167(1): 366-373.

[45] Kalogeropoulos N, Scoullos M, Vassilaki-Grimani M et al. Vanadium in particles and sediments of the northern Saronikos Gulf, Greece. Science of the Total Environment, 1989, 79(3): 241-252.

[46] Miller SLSM, Anderson MJ, Daly EP et al. Source apportionment of exposures to volatile organic compounds. I. Evaluation of receptor models using simulated exposure data. Atmospheric Environment, 2002, 36(22) : 3629-3641. 